\title{
The Fifth Cell
}

\section{Correlation Bias in U.S. Census Adjustment}

by Kenneth W. Wachter and David A. Freedman

Technical report number 570

Department of Statistics

University of California, Berkeley

To appear in Evaluation Review

Friday, 17 December 1999

Corresponding address:

Kenneth W. Wachter

Dept. of Demography, UCB

2232 Piedmont Avenue

Berkeley, CA. 94720-2120

wachter@demog.berkeley.edu

\section{AUTHOR'S NOTE}

This research was supported by a grant from the William H. Donner Foundation. The authors have served as consultants to the Freshpond Institute and as expert witnesses for the government in litigation over proposed adjustments of the 1980 and 1990 censuses. 


\section{The Fifth Cell}

\section{Correlation Bias in U.S. Census Adjustment}

One form of error that can affect census adjustments is correlation bias, reflecting people who are doubly missing-from the census and from the adjusted counts as well. This paper presents a method for estimating the total national number of doubly-missing people and their distribution by race and sex. Application to the 1990 U.S. census adjustment leads to an estimate of 3 million doubly-missing people. Correlation bias is likely to be a serious problem for census adjustment in 2000. The methods of this paper are well suited for measuring its magnitude.

\section{CORRELATION BIAS}

The U.S. Census Bureau plans to adjust the census in the year 2000 using the statistical technique called "dual-system estimation." Dual-system estimation is intrinsically subject to a form of error called "correlation bias." Correlation bias occurs because people who are hard to find for the census enumerators are also likely to be hard to find for the sample survey workers who gather the data needed to calculate the adjustment. The "correlation" in correlation bias is between propensities to be missed. This bias means that some number of people are "doubly missing"- missing from the census counts and from the adjusted counts as well. The Dual-System Estimator (DSE) is conventionally written, in a fashion described below, as the sum of four cells in a table of numbers. The doubly-missing people constitute a "Fifth Cell," which would have to be added to the DSE to achieve full population coverage.

Building on research over the last decade, this paper develops a method for estimating the total national number of doubly-missing people, that is, the total effect of correlation bias. The method is applied to 1990 data and is suitable for application in 2000. The Census Bureau's “Accuracy and Coverage Evaluation" (ACE) program for adjusting the census enumeration in 2000 is modeled closely on the "Post-Enumeration Survey" (PES) program of 1990. The order of magnitude for correlation bias estimated here for 1990 is therefore a reasonable preliminary indicator of the likely scale of the problem in 2000.

The Supreme Court ruled on 25 January 1999 that adjusted figures may not be used to apportion Congressional seats among the states. It did not rule on the constitutionality of adjustment for purposes of redistricting or distribution of federal funds. The Federal Government is planning to issue adjusted census figures 
which are likely to be used for those purposes. The adjusted population shares of states, counties, cities, electoral districts, and other jurisdictions depend on how one allocates people missing from the census to their places of residence. Correlation bias is a particular concern because, for the doubly-missing people, there is no information about places of residence.

The analysis in this paper leads to an estimate of about three million doublymissing people in 1990. For comparison, the overall net national undercount in 1990 estimated by the Census Bureau's program of Demographic Analysis is 4.68 million. On a percentage basis, black males are much more heavily represented among the doubly-missing than other groups. As discussed in Section 6, there is reason to believe that the concentration of doubly-missing people in certain parts of the country- "differential correlation bias"-was responsible for the bizarre pattern of changes in the population shares of states implied by the 1990 adjustment.

Correlation bias, like other forms of non-sampling error, is not reduced by raising the sample size. The $2000 \mathrm{ACE}$ is to have a sample size of about 300,000 housing units, as compared to the 1990 PES sample of about 165,000. The Census Bureau has not yet developed any plan for dealing with differential correlation bias, and reasons for expecting a smaller fifth cell in 2000 than in 1990 are not readily apparent.

\section{BACKGROUND}

Formal treatment of the assumptions underlying the DSE and models for correlation bias are given by Wolter (1986) and Freedman, Stark, and Wachter (1999). The DSE extends "capture-recapture" techniques pioneered in field biology. For human populations, capture is in the census and recapture is in a survey (like the PES or ACE) following the census. In practice, there are people who tend to be missed by any routine household-by-household data collection system, and go unreached by both the census and the survey. But the DSE assumes that, within each group to which the formula is being applied, the probability of being missed in the survey is the same for those counted in the census as for those missed in the census. It is the failure of this "independence assumption" that creates correlation bias in the adjusted count.

The Dual-System Estimator is conventionally expressed as a sum of four cells in the table illustrated below. Three cells are observed, representing (1) people correctly enumerated in the census who match people found in the survey, (2) people correctly enumerated in the census omitted from the survey, and (3) people omitted 
by the census correctly found in the survey. The fourth cell is not observed. Instead, it contains a stylized allowance for people omitted from both the census and the survey. The allowance is calculated under the independence assumption of zero correlation bias, and equals the product of (2) and (3) divided by (1). This fourth cell is part of the DSE and it is added into the adjusted count. The people omitted from both census and survey in excess of this allowance are missing from the whole DSE. These are the doubly-missing people who make up the fifth cell.

\begin{tabular}{lccc}
\hline & \multicolumn{2}{c}{ In DSE } & Not in DSE \\
& In Survey & Not in Survey & Not in Survey \\
\hline In Census & $(1)$ & $(2)$ & - \\
Not in Census & $(3)$ & $(4)=(2) \times(3) /(1)$ & - \\
Not in Census & - & - & $(5)$ \\
\hline
\end{tabular}

The table contains numbers for census "correct enumerations," not for raw census counts. At an earlier stage, census counts are reduced by estimates of "erroneous enumerations" like duplications and fabrications, and for certain personrecords imputed into the census. In the ACE as in the PES, dual-system estimates are calculated separately for each post-stratum. The post-strata are groups of people defined partly by demography and partly by geography. The Census Bureau has not yet announced the post-strata for 2000. For the 1990 proposed adjustment, there were 1392 post-strata. For a later proposal to adjust the post-censal estimates, there were 357. Correlation bias affects the adjustments at the level of estimates for post-strata, and through the post-strata it affects the adjusted shares of states, counties, cities, and other areas.

Necessarily, the census and the post-enumeration survey shed no light on the numbers of doubly-missing people in any group or area, since these are the people invisible to such systems. However, there are two sources of aggregate information which, in combination, give a fix on the total of doubly-missing people in the nation as a whole. These two sources are the national population estimates from the Census Bureau's program of Demographic Analysis (DA) and the measurements of biases due to processing errors in the PES from the Bureau's program of Evaluation Studies. These sources and the estimation technique based on them are described 
in Section 3. Taken together, they permit the number of doubly-missing people to be estimated by a form of residual calculation.

Several proposals have been made for other techniques which could theoretically detect some portion of the doubly-missing people by exploiting additional sources of data where available. Triple-system estimation requires three data collection enterprises attempting to cover the same universe of people. Typically, these are a census, a survey, and an administrative list (perhaps compiled from multiple partial lists). An experimental administrative list of this kind was created for the 1988 Dress Rehearsal census in St. Louis, Missouri. Some members of the population out of reach of the census and the survey may be within reach of the administrative list. There is still no direct information on the numbers of triplymissing people, and an assumption analogous to the independence assumption in dual-system estimation must be built in to the estimator. The advantage is that the conditional independence assumption can be less sweeping than the independence assumption of the DSE. The disadvantage is the need to choose among many different conditional independence assumptions, each leading to a different formula. Zaslavsky and Wolfgang (1993) pioneered this approach with an illustrative application to the 1988 Dress Rehearsal.

A complementary approach was taken by Alho et al. (1993), modeling capture probabilities for individuals with logistic regression models based on various available covariates. More sophisticated modeling of capture probabilities was combined with triple-system estimation by Darroch et al. (1993). They showed that different choices of assumptions led to dramatically different estimates of total correlation bias for selected post-strata. None of these approaches has generated estimates of total correlation bias at the national level as developed here.

The Census Bureau published conflicting estimates of correlation bias in its P-13 and P-16 evaluation projects. Selected results are found in Bell (1993) and Mulry and Spencer (1993). Mistakes in the interpretation of the P-13 estimates and in the construction of the P-16 estimates make them useless as estimates of total correlation bias; see Fay and Thompson $(1993,76)$. Properly interpreted, however, the P-13 results in Bell (1993) shed light on the difference between doubly-missing men and doubly-missing women and turn out to be consistent with the estimates in Section 4. 


\section{ESTIMATES}

The approach here to estimating total correlation bias relies on the following equation:

$$
\mathrm{PES}-\mathrm{MB}+\mathrm{CB}=\mathrm{DA}
$$

The term PES is the total adjusted population as estimated by the post-enumeration survey, while MB is the measured net upward bias in PES from processing errors identified in the Census Bureau's Evaluation Studies. CB is the unmeasured downward bias in the PES from correlation bias, and DA is the total population as estimated by Demographic Analysis. The PES acronym temporarily does double duty, standing for (i) the Post-Enumeration Survey and (ii) the total adjusted population based on the Survey. Likewise, DA stands both for Demographic Analysis and for the total estimated from it.

The terms PES, MB, and DA are all observed, so the unknown CB can be calculated by subtraction. In 1990, with the intermediate estimates of MB to be described below, the equation gives

$$
\begin{aligned}
\mathrm{CB} & =\mathrm{DA}-\mathrm{PES}+\mathrm{MB} \\
& =253.39-253.98+3.63 \text { million } \\
& =3.04 \text { million }
\end{aligned}
$$

The larger the measured bias and the higher the DA estimates, the larger is the estimate of correlation bias.

Each of the two sources which go into this calculation will now be described. First is Demographic Analysis (DA), capitalized to distinguish it from generic analysis by demographers. DA is a technique for generating national population estimates by age, race, and sex from administrative records. Descriptions may be found in Fay et al. (1988), Freedman (1991), Himes and Clogg (1992), Robinson et al. (1993) and in the Bureau's D-1 to D-11 1990 Evaluation Project Reports. See also the discussion by Darga (1999). The official figures used here are taken from Table 2, Appendix 1, of the Decision of the Secretary of Commerce, U.S. Department of Commerce (1991).

The data for DA originate from birth and death certificates, Medicare rolls, and related administrative records augmented by guesses at immigration and emigration. The use of DA for inferences about correlation bias relies on the expectation that birth and death registration include many or most of the people who are not 
picked up in household-by-household enumeration and survey efforts. If, contrary to this expectation, DA tends to miss the people omitted by the census and the PES, then the true levels of correlation bias would exceed the estimates.

Racial classification practices differ between DA and the Census and PES. Totals in this paper incorporate the Bureau's corrections for this effect in breakdowns of census numbers and net undercounts by race. A further correction could have been made in the subtraction of PES figures from DA figures, but this correction would have been too slight to be worthwhile.

The second source, which is combined with DA in the estimation process, consists of measurements of biases in the PES other than correlation bias. These biases arise from identifiable kinds of processing error, under the general rubric of "non-sampling error" as distinct from "sampling error." There are errors in matching census records with survey records, in coding geographical location, in detecting fabrications, in implementing computer processing, in handling late census returns, and so forth. These errors were measured in the Bureau's 1990 Evaluation Projects, partly on the basis of an Evaluation Followup Survey done after the PES. Details are found in the 1990 P-Project Reports. See also Mulry and Spencer (1993), Breiman (1994), and Fay and Thompson (1994).

For example, the P-7 Evaluation Study included an experiment in re-matching a subsample of PES and census records. P-7 indicated that a number of people from the census enumeration who were classified as failing to match people in the PES should really have been classified as matches. These people were added to the PES estimate for total population when they should not have been. Subtracting them reduces the PES total. Some corrections increase the PES-based total, but most reduce it. The net effect is a substantial reduction. Subsample sizes for evaluation studies are small compared to the PES, so bias estimates are only available at high levels of aggregation. They cannot be readily used to produce a bias-corrected PES for states or local areas, but they are well-suited for calculations at the national level.

Alternative totals for measured bias are available. The Bureau's original tabulations were published on a tight time schedule in the P-16 Report on 1 July 1991. Subsequently, the Bureau identified additional biases. A computer coding error was discovered, which added 1,018,000 to the bias estimates. Rematching of 104 extreme sample blocks from the PES brought the increment in measured bias up to 1,266,320, as discussed by Fay and Thompson $(1993,74)$, and Freedman and Wachter $(1994,533)$. The Bureau never issued revised versions of the P-16 tables for the measured biases, but implied totals are obtained by merging Table 19 of 
the P-16 Report with Attachment 7 of the Report of the Committee on Adjustment of Post-Censal Estimates, U.S. Bureau of the Census (1992) discussed further in U.S. Bureau of the Census (1993). These results are called "merged Bureau" totals. Independent analysis of the same data by Breiman (1994) produced further revisions. Some of Breiman's revisions are not in dispute while others are. The average between the merged Bureau totals and Breiman's totals supply the "intermediate" totals chosen for the tables here.

Table 1 shows the estimation of correlation bias using each alternative total for measured bias. The central estimate amounts to about three million doubly-missing people. The alternatives differ by a bit over half a million up and down.

TABLE 1: Estimates of Total Correlation Bias. Column $(3)=(1)+(2)$. Rounded to thousands; for detail, see the appendix.

\begin{tabular}{lccc}
\hline & DA minus & Measured & Correlation \\
& PES & Bias & Bias \\
& $(1)$ & $(2)$ & $(3)$ \\
\hline Merged Bureau & $-585,000$ & $3,014,000$ & $2,428,000$ \\
Intermediate & $-585,000$ & $3,628,000$ & $3,043,000$ \\
Breiman & $-585,000$ & $4,243,000$ & $3,658,000$ \\
\hline
\end{tabular}

Both inputs to this calculation, the DA totals and the measured biases, are subject to uncertainty. The uncertainty in the measured bias will be discussed first. A rough and ready sense of this uncertainty is given by the range between the merged Bureau estimate and Breiman's estimate in Table 1. There are systematic factors which could be argued to narrow the range. These include terms in Breiman's Table 15 that are not in dispute and that would raise the lower estimate, along with known problems in the imputation routines which would probably, on balance, reduce the upper estimate, as discussed by Wachter (1993a) and Brown et al. (1999). On the other hand, although the original error bars in the P-16 Report were rendered obsolete by the discovery of the much larger required revisions, the component of sampling error in the Evaluation Followup Survey incorporated into these bars remains relevant, and would prevent too much narrowing of the range. The standard error quoted in Table 19 of the P-16 Report for the estimate of total measured bias 
amounts to about 275,000 people. A range of plus or minus two standard errors would be only a little less than the range in Table 1.

The Bureau's 95\% subjective uncertainty interval for the DA estimate (developed in the D-11 Project) stretches from 252.90 up to 257.20 million people; also see Robinson et al. (1993). With the intermediate estimates of measured bias, the corresponding interval for correlation bias would go from 2.55 to 6.85 million. With the merged Bureau estimates, it would go from 1.93 to 6.23 million; with Breiman's estimates, from 3.16 to 7.46 million. Thus, if the D-11 estimates of uncertainty are accepted, the amounts amounts of correlation bias could be much higher but not very much lower than 3 million. With the lower figure for measured bias, the true population would have to be three times as far from the DA estimate as the Bureau's low-side uncertainty allowance to bring correlation bias below a million people.

The Bureau's uncertainty intervals for DA are controversial. The D-11 derivations incorporate stylized assumptions about the cancellation of errors from various sources which amplify the right-hand skewing of the interval and shorten its length. A realistic uncertainty interval should probably be broader and less emphatically skewed toward the high side. However, the lower the true population is hypothesized to fall below the DA estimate, the closer it would come to the total from the census enumeration and the further from the total from the adjustment. If the error in the DA total were above 2.05 million, the census count for total population would be closer to the truth in raw numerical accuracy than the adjusted count. Only at such levels would correlation bias become negligible. In other words, given the levels of measured bias in 1990, for correlation bias to be small, the raw census count would have to be closer to the mark than the adjusted count.

In summary, there are uncertainties in the total national amount of correlation bias. Assumptions which would lead to low numbers of doubly-missing people would tend to bring the accuracy of adjustments into doubt in other respects. High numbers of doubly-missing people, on the order of five or six million, are consistent with the Bureau's own assessments of uncertainties in DA, but those assessments are debatable. A total of about three million doubly-missing people seems to be the most reasonable estimate on the basis of the available information.

\section{CORRELATION BIAS BY SEX AND RACE}

The national population estimates from DA are broken down by race (black or non-black), sex, and age. Partial information on the breakdown of measured bias 
by race and sex is also available, as discussed below, permitting an approximate reconstruction of the composition of correlation bias by race and sex. The starting point is the tabulation of net census undercounts estimated from the PES and from DA shown in Table 2.

TABLE 2: Estimated net census undercounts, by race and sex, from the 1990 Post-Enumeration Survey and from Demographic Analysis, U.S. Department of Commerce (15 July 1991), Appendix 1, Table 2. Rounded to thousands. "Other" is non-black, including whites and Asians.

\begin{tabular}{lcrr}
\hline & $\begin{array}{c}\text { Post Enumeration } \\
\text { Survey }\end{array}$ & $\begin{array}{c}\text { Demographic } \\
\text { Analysis }\end{array}$ & Difference \\
\hline Black Males & 804,000 & $1,338,000$ & $+534,000$ \\
Black Females & 716,000 & 498,000 & $-218,000$ \\
Other Males & $2,205,000$ & $2,142,000$ & $-64,000$ \\
Other Females & $1,544,000$ & 706,000 & $-838,000$ \\
Total & $5,269,000$ & $4,684,000$ & $-585,000$ \\
\hline
\end{tabular}

The PES-based population totals implied by Table 2 actually exceed the DA population totals for both racial groups of females and for non-black males. These over-estimates result from the processing errors in the PES. Corrected for these measured biases, the PES totals fall comfortably below the DA totals. For black males, the pattern is very different. The PES found about half a million fewer black males than the DA estimate. As a result, the race-sex composition of the undercount obtained from DA is strikingly different from that obtained from the PES. The percentage of black males among undercounted persons according to DA is almost twice as large as the percentage according to the PES.

Table 3 shows the reconstruction of total correlation bias by race and sex. The first column comes from Table 2. The second column uses the intermediate estimates of measured bias. The Bureau's tabulated percentage figures for bias in the 13 Evaluation Strata supply a breakdown by minority versus non-minority status rather than by black and non-black race, and males and females are pooled. For Table 3, a proportional allocation by race and sex has been made within the 
Evaluation Strata; the race-sex composition of these 13 strata can be recovered from the 1392 post strata with high accuracy. Proportional allocation makes the assumption that within each Evaluation Stratum measured biases for blacks and Hispanics are at roughly the same level, and the same is true for men and women. Such an assumption cannot be pushed very far, but it may serve for a broad summary like Table 3.

TABLE 3: Correlation bias in 1990 by race and sex. "Other" is nonblack, including whites and Asians. Measured bias is from intermediate estimates with proportional allocation.

\begin{tabular}{lcccc}
\hline & $\begin{array}{c}\text { DA } \\
\text { minus } \\
\text { PES }\end{array}$ & $\begin{array}{c}\text { Allocated } \\
\text { Measured } \\
\text { Bias }\end{array}$ & $\begin{array}{c}\text { Implied } \\
\text { Correlation } \\
\text { Bias }\end{array}$ & $\begin{array}{c}\text { CB As \% } \\
\text { of Subgroup } \\
\text { Population }\end{array}$ \\
\hline Black Males & $+534,000$ & 353,000 & 887,000 & $5.6 \%$ \\
Black Females & $-218,000$ & 386,000 & 169,000 & $1.0 \%$ \\
Other Males & $-64,000$ & $1,414,000$ & $1,350,000$ & $1.2 \%$ \\
Other Females & $-838,000$ & $1,475,000$ & 637,000 & $0.6 \%$ \\
Total & $-585,000$ & $3,628,000$ & $3,043,000$ & $1.2 \%$ \\
\hline
\end{tabular}

As Table 3 shows, correlation bias in 1990 was particularly pronounced among black males. Those doubly-missing black males constitute nearly $6 \%$ of all the black males in the United States and correlation bias amounts to $66 \%$ of the whole net census undercount of black males as estimated from DA. This outcome accords with common-sense expectations, which recognize black males as among the hardest groups to reach with household-by-household data collection systems like the census, the PES, or the ACE. The prominence of correlation bias in this group, although it is not surprising, is serious. The PES, missing on a net basis most of the black males that the census missed, can hardly be expected to reflect the true geographical distribution of net census undercount in 1990. A similar outcome for ACE in Census 2000 would undermine hopes for accurate adjustment of census shares. 


\section{THE CENSUS BUREAU'S P-13 AND P-16 STUDIES}

Some corroboration of the estimates of total correlation bias presented in Sections 3 and 4 is provided by the Bureau's P-13 Evaluation Project, "Use of Alternative Dual System Estimators to Measure Correlation Bias." The P-13 Report was issued on 12 June 1991 and is summarized by Bell (1993). The calculations in P-13 start from the DA population estimates for a $6 \times 2 \times 2$ cross-classification, with 6 age groups, 2 races (black and non-black), and 2 sexes. See Table 5 of the P-13 Report. That table differs in some points of detail from the data in U.S. Department of Commerce (1991) used in the present paper. The DA counts in P-13 are evidently restricted to the so-called "P-universe" covered by the sampling frame of the PES. (The P-universe excludes the institutional population and some other groups like the inhabitants of remote Alaska, amounting to 4.37 million people.) Reconciliation of racial classification between DA and the PES may also be handled differently; the documentation is unclear.

In any case, the DA data in P-13 supply a set of ratios of males to females by age group and race. It is then possible to ask how many extra men in each group would have to be added to the DSE in order to make the sex ratios for the 12 age-race groups match those from DA. These numbers are called $\Delta$ in $\mathrm{P}-13$ and $D$ in P-16. They were not published in the Bureau's reports, but are shown in Table 4. The total in all cells amounts to 1.65 million people.

Table 4. Extra males for P-13 calculation by race and age.

\begin{tabular}{lrrrrrr}
\hline Age & $0-9$ & $10-19$ & $20-29$ & $30-44$ & $45-64$ & $65+$ \\
\hline Blacks & $-27,923$ & 3,996 & 257,658 & 271,173 & 221,766 & 38,086 \\
Others & 6,333 & 43,529 & 13 & 461,926 & 278,444 & 97,319 \\
\hline
\end{tabular}

Regarded as estimates of overall correlation bias in the PES, the numbers in Table 4 would be absurd. Only 13 non-black men would be missing from the prime age group from 20 to 29 inclusive. Black boys below age 10 would show negative correlation bias of more than 27,000. Obviously, something is wrong. The mistake is not in calculating the numbers but in treating them as estimates of 
overall correlation bias. Careful inspection of the methods in P-13 and Bell (1993) leads to a different interpretation which makes the numbers plausible.

Within each age-race group, the P-13 number for extra males can be expressed in the following form:

$$
\phi\left(\mathrm{P}_{\mathrm{F}}+\mathrm{MB}_{\mathrm{F}}-\mathrm{CB}_{\mathrm{F}}\right)-\left(\mathrm{P}_{\mathrm{M}}+\mathrm{MB}_{\mathrm{M}}-\mathrm{CB}_{\mathrm{M}}\right)
$$

Here, $\phi$ is the ratio of males to females from DA, while $\mathrm{P}$ is the notional true population. $\mathrm{MB}$ is measured bias, and $\mathrm{CB}$ is correlation bias. The subscripts $\mathrm{M}$ and $\mathrm{F}$ signify males and females. Bell assumes that the sex ratio from DA reflects the true sex ratio, so that

$$
\phi \mathrm{P}_{\mathrm{F}}=\mathrm{P}_{\mathrm{M}}
$$

Under this assumption, the contribution from measured bias would cancel out if measured bias were the same proportion of the true population for males as for females in each group-in other words, if

$$
\phi \mathrm{MB}_{\mathrm{F}}=\mathrm{MB}_{\mathrm{M}}
$$

If both (3) and (4) were true, then Bell's estimate of extra men in (2) would reduce to

$$
\mathrm{CB}_{\mathrm{M}}-\phi \mathrm{CB}_{\mathrm{F}}
$$

For values of the sex ratio $\phi$ equal to 1.00 , the quantity given by (5) reduces to the excess of the correlation bias for men over that for women. Sex ratios below 1.00 imply results from (5) greater than this excess. Sex ratios typically exceed 1.00 at birth but tend to fall with age, due to the female advantage in survivorship. Observed sex ratios from DA for blacks fall below 1.00 at all adult ages, while those for non-blacks straddle 1.00, gradually falling with age. This pattern should make Bell's total for extra doubly-missing men a modest overestimate. As it turns out, Bell's total of extra men, 1.65 million, is just about $15 \%$ larger than the excess of doubly-missing men over doubly-missing women of 1.43 million estimated by the methods of this paper (Table 3 ). Thus, the additional detail about age groups and the alternative assumptions used by Bell lead to answers quite consistent with the answer obtained here.

Bell's numbers were one of the ingredients for the Bureau's "Total Error Model" developed in the P-16 Evaluation Project. ${ }^{1}$ Problems with the P-16 numbers are discussed by Fay and Thompson $(1994,76)$ and Freedman and Wachter $(1994$, 
533-534). Documentation in the P-16 Report and in Mulry and Spencer (1993) is limited. The effort required to reconstruct the steps in the P-16 calculation delayed widespread recognition of the problems. Unfortunately, various authors have relied on the mistaken numbers, including Erickson, Fienberg, and Kadane (1994) and Belin and Rolph (1994). Misinterpretation of Bell's numbers lead Cohen, White, and Rust $(1999,81)$ to a serious underestimate of the magnitude of correlation bias.

\section{SHARE CHANGES}

Correlation bias can have a strong impact on accuracy because the doublymissing people are absent from their true locations in the adjusted counts. The areas where these people reside ought to have larger positive adjustments than they do. When counts are converted to shares via division by total population, the shares of areas with concentrations of doubly-missing people are depressed and the shares of other areas are inflated. Three million doubly-missing people is a substantial number relative to the the 5.27 million net undercount estimated and allocated to geographical areas by the PES. Population shares of many areas as calculated from the census could thus be carried in the wrong direction by the adjustment, because of correlation bias.

Comparing bias to net undercount is meaningful because adjustments to areas of significant size are almost all positive. Every state has a positive adjustment. All but 3 of 194 cities over 100,000 population and all but 12 of 512 counties over 100,000 population have positive adjustments, as shown in Tables 2 and 3 of Appendix 4 of U.S. Department of Commerce (1991). This pattern is quite general. ${ }^{2}$ For practical purposes, the process of adjustment is taking a net total of 5.27 million undercounted people, and splitting them up among states and sub-state jurisdictions.

With these considerations in mind, it is worthwhile to compare the pattern of share changes that adjustment might be expected to produce with the pattern actually produced in 1990. Conventional wisdom holds that differential undercounts by race and ethnicity are the driving factor behind inaccuracies in census shares, and that adjustment should favor states with large minority and inner-city populations. These expectations are at the root of the political impetus towards census adjustment. On these grounds, the changes in state shares produced by adjustment would be expected to form a pattern across the country. There should be a band of plusses (increases in shares) sweeping across the industrial states of the northeast and midwest, with their urban and minority concentrations. A band 
of minuses (decreases in shares) would show up among the more agricultural states of middle America. Another band of plusses would appear in the west and south, from California through Texas and Florida, with their diverse minority populations and urban centers.

In 1990, the band of plusses in the west and south appeared as expected. But the band of plusses in the northeast was nowhere to be seen. Instead, the ten states with the biggest share decreases were all northeastern and midwestern states with large minority or central city populations. Ordered by the size of decrease in share, they are Pennsylvania, Ohio, Massachusetts, Michigan, Illinois, Indiana, Wisconsin, New York, New Jersey, and Connecticut.

The pattern is visible in Figure 1, a map of the United States showing the changes in state shares that would have been produced by the 1990 adjustment. The size of each plus or minus symbol is proportional to the size of the share change. The largest increase in share is for California, with +1956 parts per million. The largest decrease is for Pennsylvania at -695 parts per million. The median absolute change is 75 parts per million. Some 28 of the states (and the District of Columbia) have share changes smaller than 100 parts per million. These states are left unmarked in Figure 1. The pattern of increases and decreases is largely determined by estimated gross omissions, but in a few states including New York estimated erroneous enumerations play an important role.

The increases for California and Texas and the sunbelt, with their large minority populations, are consistent with common-sense expectations. It is not surprising that there are plusses on these states. But it is surprising that these states are not joined by plusses on New York, Pennsylvania, Illinois, and their ilk.

Figure 3 suggests that adjustment went awry in 1990. Correlation bias of the size estimated in this paper is more than enough to account for such an outcome. Consider the ten states, all in the northeast or midwest, with losses in share of more than 200 parts per million. How many doubly-missing people would have to be added into the populations of each of these states to erase at one blow the losses in share of all of them? The answers are shown in Table 5. 
TABLE 5: Increments Required to Erase Negative Share Changes

\begin{tabular}{rr}
\hline State & Increment \\
\hline Pennsylvania & 245,000 \\
Ohio & 206,000 \\
Massachusetts & 139,000 \\
Michigan & 142,000 \\
Illinois & 146,000 \\
Indiana & 108,000 \\
Wisconsin & 100,000 \\
New York & 171,000 \\
New Jersey & 102,000 \\
Connecticut & 70,000 \\
Total & $1,429,000$ \\
\hline
\end{tabular}

The required increments, in toto, amount to less than half the estimated number of doubly-missing people. Thus, there are more than enough doubly-missing people to account for the anomalous changes in shares. Of course, there is no direct evidence from the census or the PES as to whether the doubly-missing people belong in the losing states or not. There is, however, indirect evidence. Black males are over-represented among the doubly-missing people by nearly a factor of 5 compared to their proportions in the population. It is plausible to suppose that large numbers of them are missing from states with large, hard-to-count, centralcity concentrations of black males. These are exactly the states that turn out to lack the expected upward adjustments in shares. The PES may well have been less successful at finding people missed by the census in New York, Pennsylvania, and Michigan than in California and Texas, due to differences in housing types, density, and racial concentrations among different parts of the country.

Correlation bias that differs from area to area and so affects the accuracy of shares - differential correlation bias-is discussed further by Fienberg (1993, 75-76), Wachter (1993b, 110-113), Freedman and Wachter (1994, 514, 533-534), and Brown et al. (1999). It is prima facie likely that the anomalous pattern of state share changes in 1990 reflects the impact of differential correlation bias. This likelihood is strengthened by examining other factors that affect share changes, 
but, as it turns out, fail to account for the pattern. Chief among these is a socalled "dilution effect." Even the most urbanized states have extensive suburban and rural areas. Even states with the heaviest concentrations of minorities have majority non-minority populations. Smaller undercounts or net overcounts in such areas or among such populations would be expected to dilute the undercounts in central cities when reckoning the net undercount for a state as a whole.

People who are not minorities and who live outside central cities in the northeast and midwest have a net undercount rate of $0.3 \%$, which is lower than the rate of $1.9 \%$ for the same group in the south and west. This difference would be expected to produce some dilution effect. (The rates are calculated from post-stratum level data provided by the Bureau.) On the other hand, minorities within central cities in the northeast and midwest have a net undercount rate of $4.3 \%$, which is also lower than the corresponding rate of $5.6 \%$ for the south and west. This difference would be expected to counteract the dilution effect.

A straightforward way to judge the role of the dilution effect is to examine the changes in state shares when calculations are restricted to central cities or minorities. If the dilution effect were primarily responsible for the anomalous geographical pattern, we would expect the pattern to fade away.

Figure 2 is a map in the same form as Figure 1, but the population is restricted to people living in central cities. In other words, the count for each state is computed by summing only central-city post-strata-those with place-type codes of 1,2, and 3 , corresponding to the central-city classification of the Evaluation Strata. Since breakdowns of the institutional population are not available by race or central city residence, these calculations pertain only to people in the sampling universe covered by the PES. Figure 2 shows that the pattern of changes in shares is largely the same when calculations are restricted to central city subpopulations. Pennsylvania, Ohio, Massachusetts, Wisconsin, and New York continue to dominate the list of states with large losses in population share. Michigan and New Jersey are the two main states that move from substantial losses to modest gains. New Mexico moves from substantial gain to modest loss. The anomalous band of minuses continues to appear. The losses for the northeastern and midwestern states are not to be attributed to dilution of undercounts from up-state areas.

Figure 3 presents parallel results when the population is restricted to minorities. Illinois now has the largest loss. Ohio, Michigan, and Pennsylvania continue to show large losses, and Massachusetts, Connecticut, and Wisconsin continue with losses smaller than the threshold chosen for the map. New York and New Jersey 
switch from losses to gains. The northeastern and midwestern states are joined in the loss column by the old South. Texas moves from a large gain to a moderate loss, while California captures the lion's share of the gain. Again, the dilution effect fails to explain away the anomalous pattern.

\section{CONCLUSION}

This paper has presented a method for estimating the total amount of correlation bias at the national level in a census adjustment. The method combines national population totals based on Demographic Analysis with measurements of biases due to processing errors from evaluation studies of an adjustment process.

Applied to the adjustment proposed for the 1990 census, the method leads to a total of doubly-missing people in the 1990 PES on the order of 3 million. This total is substantial in comparison to the total net undercount estimated by the PES at 5.27 million and by DA at 4.68 million. Alternative estimates of measured bias lead to alternative totals for doubly-missing people in a range from 2.4 to 3.7 million. For the total of doubly-missing people to be much outside this range, the DA estimates of national population would need to be substantially in error. The Bureau's own assessments of uncertainties in DA favor larger rather than smaller totals of doubly-missing people.

Black males are much more heavily represented than other groups among the doubly-missing people. Their true locations might plausibly be concentrated in the metropolitan areas of the northeast and midwest, in states whose shares were subject to surprising downward adjustments from the 1990 PES. If so, adjustment in 1990 might have worsened rather than ameliorated the effects of racial differentials on the population shares of states.

Correlation bias is difficult to address, among other reasons, because small reductions in the size of the fifth cell can be counterproductive. At the margin, ingenious programs might be able to bring some additional hard-to-count people within reach of post-enumeration surveys. But, to improve population shares, there would have to be similar overall levels of success under different conditions with different groups in different places across the country. It is the uniformity of success and not the overall rate of success that matters for population shares.

Errors due to correlation bias are a serious concern for ACE, the analog of the PES in Census 2000. Correlation bias is due in large part to persons reached neither by the census nor by the post enumeration survey, so there is little specific information for designing corrective measures. The Bureau has undertaken no 
research during the decade specifically targeted at differential correlation bias, although major resources have been directed at issues with much less impact. The trends which make it increasingly difficult to achieve a fully accurate Census enumeration will also make it difficult to bring correlation bias within tolerable bounds. The size of the fifth cell in 1990 counsels against unrealistic expectations for the accuracy of adjustment in 2000 . 


\section{APPENDIX: DETAILED TABLES}

TABLE 6: Estimates of correlation bias in 1990 by race and sex by type of estimate. "Other" is non-black, including whites and Asians.

\begin{tabular}{lccr}
\hline & $\begin{array}{c}\text { DA } \\
\text { minus } \\
\text { PES }\end{array}$ & $\begin{array}{c}\text { Allocated } \\
\text { Measured } \\
\text { Bias }\end{array}$ & $\begin{array}{c}\text { Implied } \\
\text { Correlation } \\
\text { Bias }\end{array}$ \\
\hline \multicolumn{4}{c}{ Merged Bureau Estimates } \\
Black Males & $+534,147$ & 279,789 & \multicolumn{1}{c}{813,936} \\
Black Females & $-217,651$ & 288,711 & 71,060 \\
Other Males & $-63,605$ & $1,193,035$ & $1,129,430$ \\
Other Females & $-838,245$ & $1,252,166$ & 413,921 \\
Total & $-585,354$ & $3,013,701$ & $2,428,347$ \\
\multicolumn{4}{c}{ Intermediate Estimates } \\
Black Males & $+534,147$ & 352,953 & 887,100 \\
Black Females & $-217,651$ & 386,216 & 168,565 \\
Other Males & $-63,605$ & $1,413,892$ & $1,350,287$ \\
Other Females & $-838,245$ & $1,475,290$ & 637,045 \\
Total & $-585,354$ & $3,628,351$ & $3,042,997$ \\
& \multicolumn{3}{c}{ Breiman's Estimates } \\
Black Males & $+534,147$ & 426,117 & 960,264 \\
Black Females & $-217,651$ & 483,722 & 266,071 \\
Other Males & $-63,605$ & $1,634,748$ & $1,571,143$ \\
Other Females & $-838,245$ & $1,698,413$ & 860,168 \\
Total & $-585,354$ & $4,243,000$ & $3,657,646$ \\
\hline \multicolumn{4}{c}{} \\
\hline
\end{tabular}


TABLE 7: Unrounded estimates of net census undercounts, by race and sex, from the 1990 Post-Enumeration Survey and from Demographic Analysis, U.S. Department of Commerce (15 July 1991), Appendix 1, Table 2. "Other" is non-black, including whites and Asians.

\begin{tabular}{lcrr}
\hline & $\begin{array}{c}\text { Post Enumeration } \\
\text { Survey }\end{array}$ & $\begin{array}{c}\text { Demographic } \\
\text { Analysis }\end{array}$ & \multicolumn{1}{c}{ DA minus } \\
& 804,233 & $1,338,380$ & $+534,147$ \\
\hline Black Males & 715,543 & 497,892 & $-217,651$ \\
Black Females & $2,205,441$ & $2,141,836$ & $-63,605$ \\
Other Males & $1,544,050$ & 705,805 & $-838,245$ \\
Other Females & $5,269,267$ & $4,683,913$ & $-585,354$ \\
Total Undercount & $253,979,140$ & $253,393,786$ & $-585,354$ \\
Total Population & & & \\
\hline
\end{tabular}

\section{NOTES}

1. The P-13 project apportioned the extra males shown in Table 4 to the 13 Evaluation Strata by a method of proportional allocation. The P-16 project was meant to integrate these numbers with estimates of measured bias for the Census Bureau's "Total Error Model." In P-16, however, the P-13 numbers were misinterpreted as estimates of total rather than excess correlation bias. Moreover, in the course of the P-16 calculations, the P-13 allowances for three Evaluation Strata were zeroed out and only a fraction ranging from $2 \%$ to $69 \%$ of the allowances for the other strata were retained. In the end, only 592,215 of Bell's 1,652,320 extra men were retained in P-16. (These numbers are for the "raw" DSE without smoothing; numbers with smoothing are similar.) In later stages of the P-16 calculations, the remaining extra men were partly converted into women. The end result was a set of meaningless numbers labeled as correlation bias.

2. For the 1990 PES, the country was partitioned into 375 areas, defined by combinations of place type and division of the country in the post-stratification. All but 19 of these areas have positive adjustments, and the 19 negative adjustments account for only 125,000 people. Within areas, there are some tradeoffs 
between demographic subgroups, but $75 \%$ of the 1392 post-strata show positive net adjustments. Only for very small areas is it sensible to regard the adjustment as a broad-brush mix of positive and negative changes. Even at the block level, positive adjustments predominate. Of the 5180 block clusters in the PES sample, over $80 \%$ are adjusted upward.

\section{REFERENCES}

Alho, J., M. H. Mulry, K. Wurdeman, and J. Kim. 1993. Estimating heterogeneity in the probabilities of enumeration for dual-system estimation. Journal of the American Statistical Association 88:1130-1136.

Breiman, L. 1994. The 1991 census adjustment: undercount or bad data? Statistical Science 9:458-75, 521-27 (with discussion).

Cohen, M., A. White and K. Rust. 1999. Measuring a changing nation: modern methods for census 2000. National Academy Press, Washington, D.C.

Darga, I. 1999. Sampling and the census. The AEI Press, Washington, D.C.

Darroch, J.N., S. E. Fienberg, F. V. Glonek, and B. W. Junker. 1993. A three-sample multiple-recapture approach to census population estimation with heterogeneous catchability. Journal of the American Statistical Association 88:1137-1148.

Fay, R. E. and J. H. Thompson. 1993. The 1990 post enumeration survey: Statistical lessons, in hindsight. Proceedings, Bureau of the Census Annual Research Conference. Bureau of the Census, Washington, D.C.

Fay, R. E., J. S. Passel, J. G Robinson and C. D. Cowan. 1988. The coverage of the population in the 1980 census. U.S. Department of Commerce, Government Printing Office.

Fienberg, S. E. 1993. The New York City census adjustment trial: Witness for the plaintiffs. Jurimetrics 34:65-83.

Freedman, D. 1991. Adjusting the 1990 census. Science 252:1233-1236.

Freedman, D. A., P. B. Stark, and K. W. Wachter. 1999. A model for correlation bias, heterogeneity, and ratio estimator bias in census adjustment. Technical Report 557, Department of Statistics, U.C. Berkeley.

Freedman, D. A. and K. W. Wachter. 1994. Heterogeneity and census adjustment for the post-censal base. Statistical Science 9:476-85, 527-37 with discussion. 
Himes, C. and C. Clogg. 1992. Demographic analysis as a method of estimating population by age, sex, and race. Population Index 58:587-607.

Hogan, H. 1993. The 1990 post-enumeration survey: Operations and results. Journal of the American Statistical Association 88:1047-60.

Mulry, M. 1991. 1990 post enumeration survey evaluation project P16: Total error in PES estimates for evaluation post strata. Bureau of the census, Washington, D.C.

Mulry, M. and B. Spencer. 1993. Accuracy of the 1990 census and undercount adjustments. Journal of the American Statistical Association 88:1080-91.

Robinson, G., B. Ahmed, P. Das Gupta, and K. Woodrow. 1993. Estimation of population coverage in the 1990 United States census based on demographic analysis. Journal of the American Statistical Association 88:1061-1071.

U.S. Bureau of the Census. 1992. Assessment of accuracy of adjusted versus unadjusted 1990 census base for use in intercensal estimates: Report of the committee on adjustment of postcensal estimates. 7 August 1992.

U.S. Bureau of the Census. 1993. Decision of the director of the Bureau of the Census on whether to use information from the 1990 post-enumeration survey PES to adjust the base for the intercensal population estimates produced by the Bureau of the Census. Federal Register 58:69-77, 4 January 1993.

U.S. Department of Commerce, Office of the Secretary. 1991. Decision on whether or not a statistical adjustment of the 1990 Decennial Census of Population should be made for coverage deficiencies resulting in an overcount or undercount of the population, explanation. Three volumes, Washington, D.C., reprinted in part in the Federal Register 56:33582-33642, 22 July 1991.

Wachter, K. W. 1993a. Ignoring nonignorable effects. Journal of the American Statistical Association 88:1161-1163.

Wachter, K. W. 1993b. The census adjustment trial: An exchange. Jurimetrics 34:110-13.

Wolter, K.M. 1986. Some coverage error models for census data. Journal of the American Statistical Association 81:336-346.

Zaslavsky, A.M. 1993. Combining census, dual system, and evaluation study data to estimate population shares. Journal of the American Statistical Association 88:1092-1105. 
Zaslavsky, A.M., and G. S. Wolfgang. 1993. Triple system modeling of census, post-enumeration survey, and administrative list data. Journal of Business and Economic Statistics 11:279-288.

\section{AUTHORS}

Kenneth W. Wachter is a professor of demography and statistics and chair of the Department of Demography, University of California, Berkeley. His research interests include mathematical and statistical demography, computer microsimulation, kinship forecasting, aging, and longevity.

David A. Freedman is a professor of statistics and mathematics, University of California, Berkeley. His research interests are in the foundations of statistics, modeling, and policy analysis. 
Figure 1

\section{State Share Changes from 1990 Adjustment}

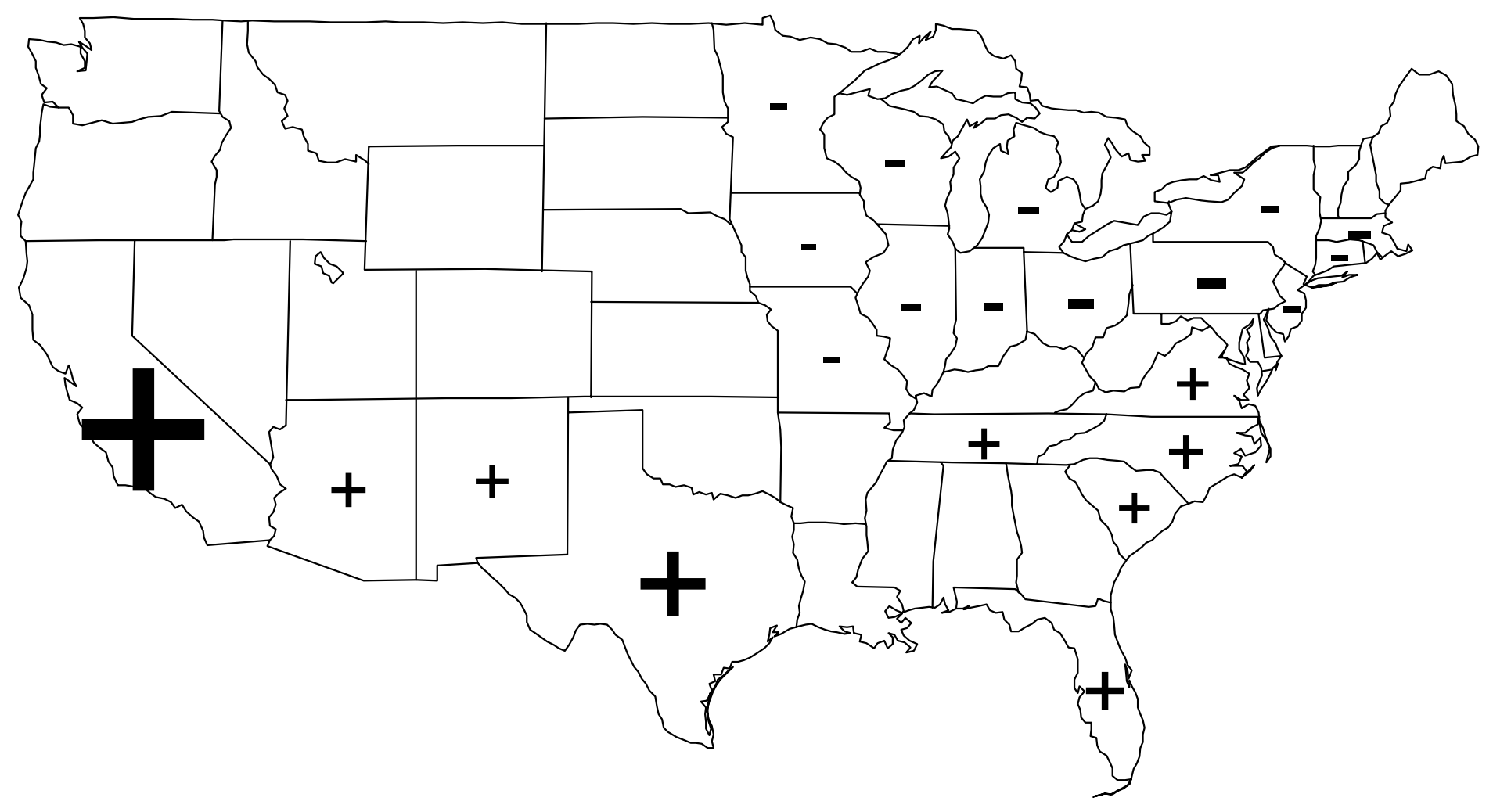

+ - Changes Exceeding 100 Parts Per Million 
Figure 2

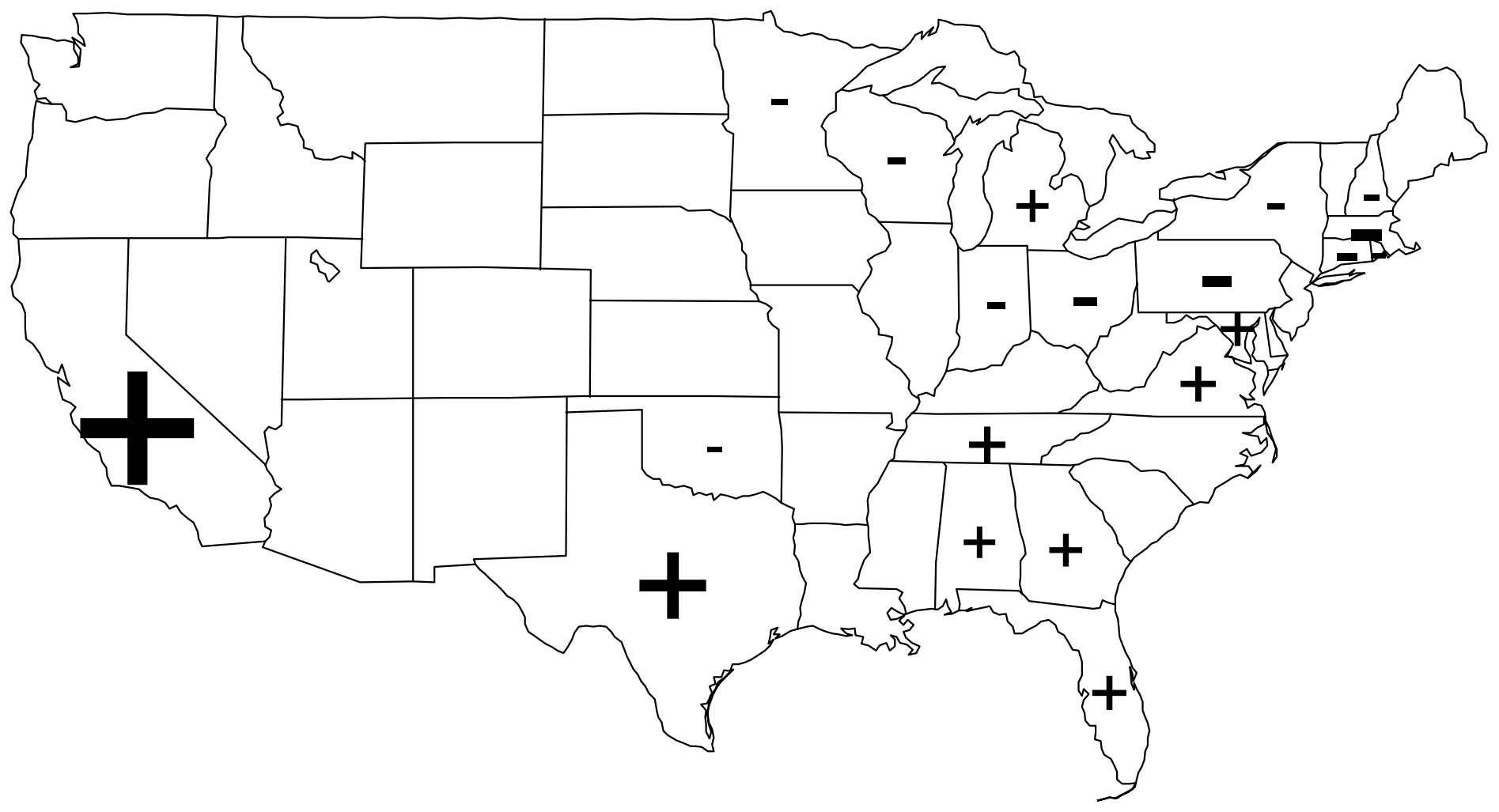


Figure 3

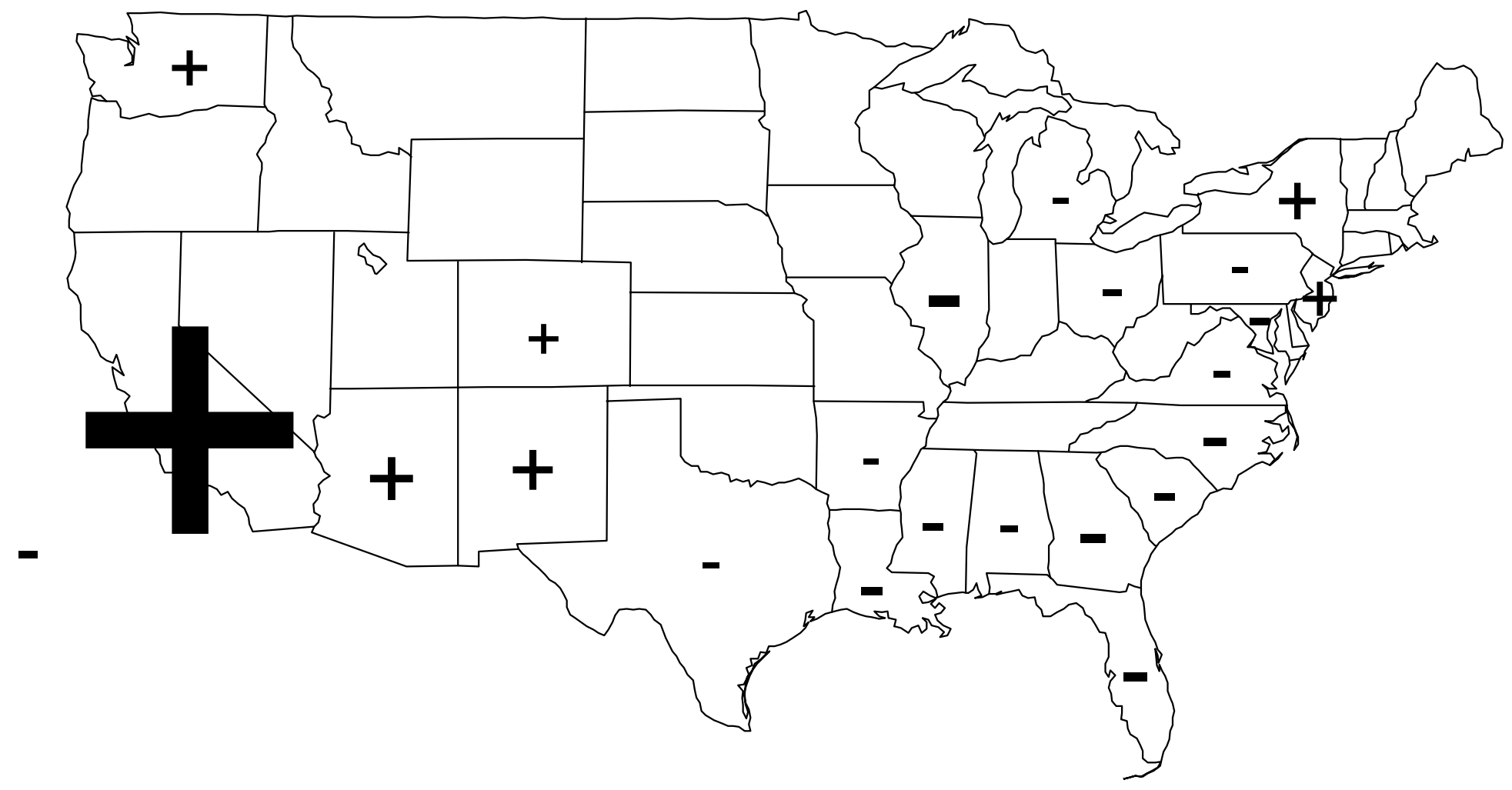

